\title{
Brincar na escola: caminhos e escolhas
}

Ana Maria Leite* Maria Lúcia Medeiros**

*Coordenadora do Projeto

Brincar: Educação Infantil

E-mail: anamaria.leite@cenpec.org.br

**Coordenadora do Projeto

Brincar: Educação Infantil

E-mail:marialucia@cenpec.org.br
Resumo: Este artigo busca conceituar a brincadeira como uma importante linguagem expressiva das crianças. Pretende refletir sobre alguns impasses encontrados entre discursos e práticas nas escolas de educação infantil em torno dessa temática. Aponta, também, a urgência da reflexão sobre as práticas para a garantia do direito ao brincar, indicando a formação lúdica do educador como um caminho possível para essa reflexão. A concepção e o delineamento deste caminho assentam-se em reflexões e experiências acumuladas ao longo do desenvolvimento das ações do projeto Brincar: educação infantil, desenvolvido pelo Cenpec em parceria com a Fundação Volkswagen.

Palavras-chave: Brincar. Infância. Formação do educador. Educação infantil. 
INTRODUÇÃO

“Esses professores não trabalham, só brincam!?”

"O que a brincadeira está promovendo?” (fala de gestor de escola de educação infantil) “O que eu vou ensinar com as brincadeiras?” (fala de professor de educação infantil)

"Por que não podemos brincar mais?" "Nós não vamos brincar hoje?" “Oba, é hora de brincar!” (fala de criança) "Essas professoras só brincam e bagunçam a sala!” "Não sabem brincar sem fazer sujeira?" "Por que vocês não brincam sem correr?" (equipe de apoio de educação infantil) “Nessa escola você não estuda, só brinca?” "Se for para brincar é melhor ficar em casa." “Nessa escola não se aprende nada, a professora só brinca com os alunos" (falas de familiares de educação infantil)

As falas acima são exemplos frequentes do que ouvimos quando iniciamos uma formação ${ }^{1}$ nas escolas públicas de educação infantil, em torno da importância do brincar para a infância. Elas evidenciam o quanto esse tema faz parte de um grande campo de tensões entre os diferentes atores presentes nessas instituições.

É muito comum encontrarmos a visão de que se a criança está indo para a escola é para estudar/aprender. E o que se concebe por aprender está ligado à aquisição de um conjunto de saberes cognitivos compartimentados em disciplinas. No caso da educação infantil, considerada por lei como etapa inicial da educação básica, entende-se por aprendizado escolar, num

As autoras coordenam o projeto Brincar: o brinquedo e a brincadeira na infância, realizado desde 2005 pelo Cenpec em parceria com a Fundação Volkswagen. Em 2013 houve algumas reformulações e ele passou a ser chamado de Brincar: educação infantil, atuando na formação continuada de educadores desse segmento. Seu foco central é refletir sobre a infância, sua cultura e brincadeiras e sobre as práticas dos profissionais da educação infantil relacionadas a essas temáticas. 
senso comum, o ato de adquirir competências para ler, escrever e contar, principalmente na visão dos familiares das crianças.

Estando o ato de brincar presente nas escolas de educação infantil, notamos que, embora valorizado, ele é endossado numa perspectiva utilitária, ou seja, que faz uso de brincadeiras para ensinar conteúdos específicos definidos, planejados e dirigidos pelo adulto. Apesar de quase todos falarem da importância do tempo de brincar, entre os próprios educadores, sejam gestores de escola ou professores que lidam diretamente com as crianças, é frequente um conflito de atitudes que se revelam na queixa de alguns professores quanto à incompreensão dos gestores em relação a tempos de brincadeira mais estendidos ou mesmo quanto à visão de seus próprios colegas, expressa no dizer de que são considerados como "aqueles que não fazem nada quando brincam". De outro lado, também os gestores responsabilizam os professores por brincarem pouco ou por não estarem à frente das brincadeiras. Há, ainda, a fala de que a brincadeira dispersa, provoca sujeira e o risco de as crianças se machucarem, adotada por muitos atores da escola, principalmente equipes de apoio e familiares.

Esse diálogo controverso apresenta diferentes ideias sobre o que é a brincadeira infantil e sua importância para as crianças, além de mostrar diversos pontos de vista sobre o papel da escola para essa faixa etária (0 a 6 anos). Também, aparentemente, revela contradições entre os discursos sobre a criança e seu desenvolvimento e as práticas educativas a ela destinadas. Evidencia-se, assim, a importância da ampliação e do aprofundamento do debate sobre essa temática.

Diante do quadro apresentado, este texto pretende discutir questões, expondo uma concepção do brincar como essência do universo infantil e problematizando as práticas escolares. Entre vários aspectos a serem transformados para o acolhimento da brincadeira na perspectiva adotada, elegemos a formação do educador como um caminho que the permita compreender melhor esse universo para acolher cada vez mais os brincares infantis, exemplificando-o no transcorrer deste trabalho.

O ponto de vista a ser apresentado procura partir das necessidades humanas das crianças de se desenvolverem integralmente consigo mesmas, com os outros e com as coisas do mundo.

Dessa forma, o texto pretende ser um subsídio a mais para ajudar os educadores a ouvir suas crianças que, com frequência, dizem, mesmo que 
não seja por palavras:

“Nós não vamos brincar hoje?”, “Oba, é hora de brincar!”.

O QUE É BRINCAR?

“Brincar é ser feliz!” (Thalissa L. C. S. Maria, diretora de educação infantil)

"Brincar é se libertar... É poder compartilhar coisas, sem medo, correr, pular, interagir com o outro, é liberdade máxima... é o auge do pensamento simbólico." (Patrícia T. L. Secches, coordenadora de educação infantil)

"Brincar é interagir com outras crianças, outras pessoas. Brincar é aprender."

(Sandra A. O. Moraes, coordenadora de educação infantil)²

De imediato, essas falas de profissionais da escola sobre o brincar ajudam-nos a discorrer sobre o nosso ponto de vista. De um lado, brincar, frequentemente, é associado a sensações de prazer, alegria, espontaneidade. De outro, são atribuídos benefícios advindos das brincadeiras: relações de aprendizagens, desenvolvimento social, corporal, emocional, cognitivo.

Há autores que defendem a ideia de a brincadeira anteceder a própria história humana. Os mamíferos brincam e, por meio disso, se desenvolvem, aprendem a atacar e a se defender. Neste texto, interessa-nos pensar o brincar para a espécie humana e, especificamente, para a infância.

Vários estudiosos de diferentes áreas do conhecimento debruçaram-se e ainda estudam, com profundidade, o universo do brincar para compreender melhor suas qualidades, as diferentes formas em que ele se apresenta, os benefícios que traz. São exemplos, dentro da Psicologia, os de Piaget (1978), Vygotsky (1998), Wallon (1981), Winnicott (1975). Relacionada à Antropologia, podemos citar os estudos de Sarmento (2009), Corsaro (2011), entre outros. Ciências como a Neurociência e a Biologia também vêm se aprofundando nessa temática.

De acordo com Verden-Zöller (2004):

Na vida diária, o que queremos conotar quando falamos em brincar é uma atividade realizada como plenamente válida em si mesma. Isto é, no cotidiano distinguimos como brincadeira qualquer atividade vivida no presente de sua realização e desempenhada de modo emocional, sem nenhum propósito que lhe seja exterior ( $p$. 144).

Ou seja, adultos e crianças brincam quando se entregam a um momento presente, em plenitude, com inteireza. Brincam, simplesmente, pelo prazer e 2 Falas retiradas de entrevistas feitas para o vídeo Caramba, carambola - o brincar tá na escola. São Paulo, Cenpec: 2013. 
vontade de brincar. É um momento de entrega e liberdade. Não há um objetivo ou intencionalidade a ser alcançado. Há a possibilidade de fazer aquilo ou não, de escolher com quem irá brincar ${ }^{3}$, onde e quando isso acontecerá. Ficamos envolvidos com a brincadeira por simples fruição, pelo prazer de desafiar a nós mesmos, pelo fato de nos relacionarmos com outras pessoas ou objetos. Temos a liberdade de interrompê-la a qualquer momento. Podemos mudar as regras de um jogo, se quisermos. A espontaneidade é parte intrínseca ninguém brinca verdadeiramente, se for obrigado a fazer isso.

Imaginar e criar são duas ações presentes o tempo todo no ato de brincar. Um galho de uma árvore pode ser espada, varinha mágica, acessório de cozinha, instrumento médico ou qualquer coisa que a imaginação permitir. Vygotsky (1998) destaca que, mesmo em um jogo de regras complexo como o xadrez, a imaginação está presente.

Da mesma forma que uma situação imaginária tem que conter regras de comportamento, todo jogo com regras contém uma situação imaginária. [...] O mais simples jogo com regras transforma-se imediatamente numa situação imaginária, no sentido de que, assim que o jogo é regulamentado por certas regras, várias possibilidades de ação são eliminadas (p.125).

Ao brincar, há uma vivência diferenciada de tempo e espaço. A criança vive o “agora eu era a filha” - presente, passado e futuro estão juntos, entrelaçados. Nessas relações, vai construindo as noções temporais.

Brincar é, também, conviver e fazer relações com outras pessoas, consigo mesmo, com objetos. Ao brincar, as crianças aprendem e fazem experiências de convivência. Negociam regras e papéis, lidam com seus desejos e frustrações, aprendem a cuidar do próximo, interagem com diferentes idades.

Brincar é um ato de conhecimento de si e do mundo. Ao acompanharmos o crescimento de uma criança bem pequena, seja qual for a sua cultura de origem, podemos notar, no seu processo de desenvolvimento, o interesse pela descoberta de sensações, de prazer, do desafio e do aprender. A criança busca seu desenvolvimento por meio de variadas experiências, entre elas, as corporais expressivas.

3 A brincadeira assume formas variadas entre as crianças e os adultos. Comumente, falamos em brincadeiras de crianças como aquelas que envolvem o corpo, o movimento, as brincadeiras de faz de conta; mas, também, podem ser consideradas brincadeiras os momentos em que estão desenhando, cantando, modelando, etc. Costumamos dizer que são diferentes linguagens expressivas que a criança tem a seu dispor e, quando entregues com inteireza a elas, transformam-nas em brincadeiras. Para o adulto, a brincadeira ou ludicidade está presente quando ele se entrega ao desfrute de uma leitura, de uma música, de uma caminhada, ou tantos outros fazeres. 
Podemos dizer que a primeira brincadeira do bebê acontece com o seu próprio corpo e com o corpo de sua mãe ou do adulto que dele cuida. Quando o bebê começa a perceber a sua mão e passa a movimentá-la aleatoriamente, aos poucos vai tomando conhecimento, por meio dos sentidos, que, com seus atos motores, toca em objetos produtores de sensações táteis, sonoras, visuais, estimuladores de sua atenção. Na repetição dessas ações vão surgindo novas descobertas e desafios corporais. Paulatinamente, seu corpo vai se desenvolvendo e the trazendo outras possibilidades como, por exemplo, andar, correr, pular. Quando a criança começa a andar, logo the vem um sorriso ao rosto, demonstrando satisfação. Ela quer continuar a fazer isso, simplesmente pelo prazer que lhe proporciona. Em seguida, busca novo desafio, correndo ou pulando. Assim, sucessivamente, vai se desenvolvendo. Sua interação com o mundo e exploração sobre ele crescem.

Na primeira infância, por meio da brincadeira e enquanto vivem muitas experiências recorrentes de movimento, tocando, balanceando e fazendo ritmos, as crianças gradualmente constituem e desenvolvem o conhecimento operacional de seus corpos em muitas configurações de redes entrecruzadas de coordenações sensório-motoras (VERDENZÖLLER, 2004, p. 166).

Também na aquisição da linguagem observamos diferentes etapas de brincadeiras sonoras, desde os balbucios, sons melódicos que a criança emite, músicas até invenções de palavras e histórias. 0 mesmo acontece com outras formas de se expressar e conhecer o mundo. Poderíamos aqui exemplificar suas representações gráficas, iniciadas gratuitamente, que vão se aperfeiçoando em traços intencionais, numa tentativa de desenhar a realidade até chegar à escrita.

Nesses processos, a criança vai explorando e conhecendo o mundo. Passa a interagir não só com o seu corpo mas com tudo o que está ao seu redor. Inserida em uma cultura, observa, fica curiosa, faz experimentações e vai construindo conhecimento em suas relações.

Logo, ao brincar, a criança assimila elementos dessa cultura, e ao agir sobre ela, também a recria. Torna-se, assim, produtora de cultura. Brincando sozinha ou com seus pares, ela dá novos significados aos elementos culturais (objetos, palavras, gestos, etc.) e, também, inventa coisas novas. "As crianças produzem uma série de culturas locais que se integram e contribuem para as culturas mais amplas de outras crianças e adultos a cujo contexto elas estão integradas. Esses processos variam ao longo do tempo e entre culturas [... ]" (CORSARO, 2011, p. 127). 
As brincadeiras de roda ou jogos de regras, por exemplo, são passados de geração a geração, carregam traços de uma determinada cultura ao mesmo tempo em que dão a liberdade para as crianças reinventarem gestos, palavras, regras, etc. Muitos deles são universais, ou seja, estão presentes em culturas distintas (povos indígenas que vivem no Brasil, comunidades africanas, asiáticas, países europeus), revelando que estão carregados de um sentido mais profundo do que possam revelar à primeira vista. Carvalho e Pontes (2003) destacam algumas motivações universais das brincadeiras, como, por exemplo, voar (nas brincadeiras de pipas) ou abrigar-se nas brincadeiras de casinhas presentes em diferentes contextos. "Pode-se pensar que tanto voar (implicando desafiar limites) quanto abrigar-se são motivações ou disposições humanas básicas, selecionadas ao longo da evolução e com expressão precoce através da ludicidade” (p. 24). Apesar de serem universais, elas se constituem na diversidade local ou grupal. Essas autoras defendem que observar crianças brincando nos "ensina sobre a natureza do humano e sobre a profunda imbricação entre evolução biológica e evolução cultural que o caracteriza" (p. 27).

Brincando, as crianças também acionam seu mundo interno. Nas brincadeiras de faz de conta, quando representam diferentes papéis, elas imitam adultos, outras crianças, personagens de histórias ou animais, e criam e recriam enredos em que expõem seus medos, angústias, alegrias, desejos e pontos de vista, como seus modos de ver a morte, a violência urbana ou doméstica. São elementos que, muitas vezes, assustam o adulto que se vê, também, questionado sobre tais assuntos. Também falam do passeio de domingo, de uma experiência feliz e bem-sucedida que tiveram, de uma história que ouviram.

Se ignoramos as necessidades da criança e os incentivos que são eficazes para colocá-la em ação, nunca seremos capazes de entender seu avanço de um estágio de desenvolvimento para outro porque todo avanço está conectado com uma mudança acentuada nas motivações, tendências e incentivos [...] A maturação das necessidades

é um tópico predominante nessa discussão, pois é impossível ignorar que a criança satisfaz certas necessidades no brinquedo. Se não entendemos o caráter especial dessas necessidades, não podemos entender a singularidade do brinquedo como uma forma de atividade (VYGOTSKY, 1998, p. 122).

Pelo ato de brincar também é propiciada a construção da autonomia: pela escolha do que querem fazer, dos objetos de que necessitam, seus parceiros, seus enredos, pela organização dos espaços.

Enfim, podemos afirmar que a brincadeira é uma ação de autoconhecimento.

É uma maneira de ela descobrir seu potencial, fazer relações, investigar, 
inventar, buscar desafios, sociabilizar-se, desenvolver-se nos diferentes aspectos (físico, psíquico, cultural, social, cognitivo), ressignificar o mundo que vê, cheira, tateia, saboreia e ouve.

Essas e outras potencialidades mostram, por si mesmas, a necessidade e importância de garantir o brincar às crianças.

Documentos como a Declaração dos Direitos da Criança da ONU, o Estatuto da Criança e do Adolescente e a Constituição Federal transformaram o brincar em direito das crianças. Isso significa que gestores públicos e cidadãos responsáveis pelas crianças precisam se engajar na garantia desse direito, gerando oportunidades, espaços e tempos para brincar. Instituições que acolhem crianças também devem se responsabilizar por esse direito. A escola infantil, espaço onde a criança passa grande parte de seu tempo, é uma delas.

PRÁTICAS EDUCATIVAS E O BRINCAR

\begin{abstract}
[A brincadeira] é um mundo aberto, incerto. Não se sabe, com antecedência, o que se vai encontrar: a brincadeira possui uma dimensão aleatória. Nela encontramos o acaso ou a indeterminação, resultantes da complexidade das causas que estão em ação. É um espaço que não pode ser totalmente dominado de fora.
\end{abstract}

(Gilles Brougère)

A escola da educação infantil é uma instituição relativamente nova ${ }^{4}$. Como tal, parece estar em busca da sua identidade. Durante os processos de formação realizados no âmbito do projeto Brincar, desde 2005, temos tido oportunidades de nos aproximar de algumas dessas escolas e ver essa busca acontecer. Quadros variados de "modo de ser escola” são encontrados. Temos observado a existência desde aqueles que mostram práticas controladoras e com exageros quanto à solicitação de produção das crianças com vistas a resultados esperados, até aqueles que particularizam o trabalho realmente para as necessidades das crianças pequenas e bem pequenas de se desenvolverem, compreenderem e ressignificarem o mundo ao qual pertencem, acolhendo o seu modo particular de ser criança.

\footnotetext{
A história da educação infantil no Brasil tem origem no período republicano, com início de atendimento de crianças em creches e jardins da infância, ou escolas maternais. Desde o início, teve um atendimento diferenciado para crianças mais pobres e mais ricas e trouxe, de sua raiz, o conflito entre assistencialismo e educação. Apenas com a LDB de 1996, creches (para crianças de 0 a 3 anos) e pré-escolas (para crianças de 4 a 5 anos) passam a integrar a primeira etapa do ensino básico. Para mais detalhes, ver Kuhlmann Jr (2000).
} 
Apesar de muitas nuances serem encontradas entre esses dois extremos de escolas, partiremos desses quadros para problematizar o lugar que a brincadeira tem ocupado nas instituições de educação infantil.

Encontramos com mais frequência escolas pautadas no controle das manifestações infantis e de suas produções. A necessidade de prestar contas do trabalho realizado faz com que equipes escolares inteiras se dediquem a justificar um processo em que a produção infantil valorizada é aquela que ocorre no papel - os famosos "trabalhinhos"

Tendo a dificuldade de olhar, ouvir e esperar, os educadores não conseguem ver os aprendizados que vão muito além daqueles previamente determinados, como os da contagem e início da geometria em uma brincadeira de amarelinha, por exemplo.

Com a necessidade do controle, são impedidos de ver quantas relações as crianças estão construindo quando elas mesmas criam os seus brincares. Impedimentos culturais e pedagógicos dificultam enxergar as diferentes aprendizagens que ocorrem, seja em um desenho, quando estão absortas nos seus “eus" contando histórias que misturam a realidade vivida e seus desejos mais profundos, seja em uma fila, esperando sua vez para pular corda, ou em qualquer outra relação de entrega - construindo castelos na areia, cantando, olhando livros e recriando histórias, pintando, modelando, conversando, subindo em árvores, em momentos individuais ou coletivos.

Nas práticas controladoras, a surpresa é um elemento do brincar que não acha espaço; mas a brincadeira traz, em si mesma, o inesperado, o imprevisto. Não se sabe, exatamente, qual será o resultado ou o caminho que será construído ao brincar.

Não se pode fundamentar, na brincadeira, um programa pedagógico preciso. Quem brinca pode sempre evitar aquilo que lhe desagrada. Se a liberdade valoriza as aprendizagens adquiridas na brincadeira, ela produz, também, uma incerteza quanto aos resultados. Daí a impossibilidade de assegurar aprendizagens, de um modo preciso, na brincadeira. É o paradoxo da brincadeira, espaço de aprendizagem cultural fabuloso e incerto (BROUGĖRE, 2006, p. 104).

A incerteza constitutiva da brincadeira quanto ao seu encaminhamento e repercussões em quem brinca não tem tido espaços de abrigo nos planejamentos de ações controladoras e muito menos na execução do que foi planejado, gerando produções das crianças com respostas previamente

5 A própria palavra "trabalhinho", no diminutivo, já expressa um valor menor à produção infantil. Também é denominado como "tarefinha". 
esperadas e predeterminadas. Um exemplo disso ocorre quando vemos, nos muitos murais das escolas por onde passamos, registros de atividades com padronização de respostas; assim, a partir de uma proposta de representação por meio de colagem, os recortes do mesmo tamanho, do mesmo papel, da mesma cor são colados na mesma posição, porém em folhas diferentes - uma destinada a cada criança.

Este tipo de escolha pedagógica, a do controle e da produção homogênea, aliado à visão de que brincar causa dispersão, bagunça e mesmo violência entre as crianças, tem provocado o impedimento das manifestações de liberdade e das diferenças.

Quando limitamos uma criança a um espaço restrito, entre quatro paredes, muitas vezes sentadas em cadeiras, sem possibilidade de expansão corporal, sem correr, pular e sem contato com a natureza - o sol, as árvores, areia -, contemos uma energia que precisa sair. No pouco tempo que tem sido destinado às brincadeiras e aos recreios escolares, esta criança que não aprendeu a lidar com seu corpo, ao fazer uso dele, o faz de forma "desajeitada”, que pode parecer, num primeiro momento, uma atitude violenta. No entanto,

O modo como uma criança vive a sua corporeidade, nos primeiros anos de vida, não é indiferente para o seu desenvolvimento. Em consequência, também não o é para o desenvolvimento de suas possibilidades de consciência individual e social, bem como para o desenvolvimento de sua capacidade de autoaceitação e aceitação do outro (VERDENZÖLLER, 2004, p.132).

Pautado no controle do corpo, do tempo, do modo de fazer, este quadro observado em muitas escolas não vem garantindo o “chão” para a vivência da corporeidade, logo, da consciência individual e social, como Verden-Zöller (2004) nos aponta.

Nelas, ainda, encontramos a falta de espaço apropriado ou, então, a não utilização adequada para otimizar tais experiências infantis. Os espaços internos são reduzidos e mal preparados e os externos, muitas vezes, inexistem ou são pouco adequados. Assim, quando há brincadeiras, elas ocorrem dentro da sala, onde, muitas vezes, só há espaços para carteiras.

Dentro de um quadro como este, o direito à brincadeira não tem podido ser, minimamente, garantido. 
O compromisso sociopolítico com a ludicidade (Art. $7^{\circ}$ - DCNEI) traz para o centro da cena o direito à brincadeira e implica o rompimento de relações de dominação etária dos adultos sobre as crianças e na superação da obsessão pelo controle. Nessa lógica, não faz sentido que as crianças permaneçam por longos períodos em espaços fechados,

enfileiradas, aguardando o comando dos adultos, como num quartel. Ao contrário, se interações e brincadeiras são apontadas como eixos norteadores da proposta curricular

$\left(\right.$ Art. $\left.9^{\circ}\right)$, as práticas pedagógicas devem estar atentas às manifestações infantis, aos desejos e interesses que as crianças expressam quando brincam livremente entre si. É esta atenção que assegura o respeito ao princípio estético de valorização da sensibilidade, da criatividade e da liberdade de expressão (Art. $6^{\circ}$ ), potencializadas quando em interação com os elementos naturais (TIRIBA, 2010, p. 5).

Este quadro apresentado coloca-nos o desafio de mudá-lo no menor tempo possível. As escolas e as redes de ensino que bebem, de um jeito ou de outro, desta fonte, precisam reverter o seu olhar e buscar fazer do centro de suas ações as crianças e suas necessidades.

Muitas outras possibilidades de escolas são vistas por nós e o quadro que se encontra no outro extremo, ou seja, aquele que busca colocar a criança como centro, pode ser inspirador para essa mudança.

A escola que procura colocar a criança como centro sabe do seu papel de acolher, preparar, ancorar o brincar de suas crianças e sabe o quão valioso é observá-las brincando. Faz uso desses momentos para (re)conhecer suas crianças, suas singularidades, descobrir e dar abrigo aos seus verdadeiros potenciais. Os adultos, sem se infantilizarem, dão vazão às criações e abrigo às diferentes maneiras como a imaginação se manifesta. São adultos que amparam as experiências vividas pelo corpo infantil.

Se a escola se assume como responsável pelo desenvolvimento particular e coletivo das crianças, atenta ao modo de ser de cada uma, ela coloca a brincadeira em primeiro plano. Dispõe de tempo e espaços. Reconhece quando a criança está entregue ao seu fazer e permite que isso aconteça. Dá o tempo necessário para viver essa entrega, reconhece que cada criança tem um tempo e um modo de envolvimento com seus fazeres (desenhando, escutando uma história, entre outros).

Para tanto, essa escola disponibiliza materiais simples e variados ao alcance de meninas e meninos - tecidos, caixas de papelão de diferentes tamanhos, objetos do cotidiano (panelas que não são mais usadas, talheres, teclados de computadores, telefones), elementos da natureza (sementes, galhos, folhas secas, árvores, areia), objetos que comumente chamamos de sucata (garrafas 
plásticas, embalagens, tampinhas), mas que, nas mãos das crianças, tornamse excelentes brinquedos, além, é claro, de brinquedos tradicionais (bonecas, carrinhos, peão, corda).

Favorecer a brincadeira em tal escola significa propiciar liberdade para a criança decidir o que, como, onde, de que jeito e com quem brincar. 0 adulto pode ser um participante dessa brincadeira ou apenas um espectador. Ele permite que a criança brinque, sem conduzi-la nem abandoná-la, proporcionando tempo e espaço necessários e mostrando-se disponível para as necessidades da criança. Ele também convida para a brincadeira, mas não a impõe.

Nesse quadro de escola, o espaço é visto como o grande chão de possibilidades e as brincadeiras das crianças são o seu maior tesouro. Além disso, o contato com a natureza torna-se premissa para as ações pedagógicas.

Cuidar das crianças significa mantê-las em contato com o universo natural de que são parte. Se o nosso compromisso é com a sua integridade e com a preservação da vida no planeta, Sol, ar puro, água, terra, barro, areia são elementos/condições que devem estar presentes no dia a dia de creches e pré-escolas (TIRIBA, 2010, p. 7).

Tendo apresentado dois quadros antagônicos de escola, um com centralidade no adulto e outro, na criança, retomamos nossa afirmação de que a realidade nos mostra existir, entre um extremo e outro, diversas nuances.

Há aqueles quadros em que, no discurso, já aparece a criança como centro, porém, as ações ainda não demonstram a realidade de tal ideia. Há outros que favorecem o brincar, mas, em muitas situações, são percebidas experiências de controle e excesso de produção homogênea.

Há muitas buscas de caminhos que procuram aliar o discurso da centralidade da criança com uma prática condizente. No entanto, a frequência com que encontramos uma prática mais controladora, nesta experiência de formação de educadores, mostra-nos que muito precisa ser feito para transformar as práticas escolares em algo mais próximo das necessidades da criança pequena e bem pequena.

Fazer valer o direito à brincadeira é urgente. Brincadeira que precisa ser entendida como forma de expressão e de estar no mundo, quando se trata de criança.

Reconhecendo o importante papel que as escolas de educação infantil têm, atualmente, na vida das crianças pequenas, acreditamos que um passo 
fundamental a ser dado começa na formação lúdica do educador. Formação que deve ter início nos cursos de Pedagogia e se estender ao longo de toda a sua vida profissional.

Por esse motivo, apresentaremos, a seguir, uma proposta de formação continuada para educadores da primeira infância, focada sobre esta temática.

\section{A FORMAÇÃO LÚDICA DO EDUCADOR DA INFÂNCIA - UM CAMINHO POSSÍVEL}

A formação inicial do professor da educação infantil tem sido tema de debates $^{6}$. Com a LDB 9.394/96, todo professor de educação infantil deve ter formação de nível superior. Se as faculdades de Pedagogia proliferaram pelo país, tornando mais acessível fazer esses cursos, o que constitui um mérito, por outro lado, assim como em outros níveis de ensino, tal realidade passa a colocar a problemática da relação entre quantidade e qualidade - que não se encontra em equilíbrio. Além disso, dentro dos cursos de Pedagogia, as matérias oferecidas pouco priorizam a criança pequena?. Para Secanechia (2011)

a invisibilidade da criança pequena no curso de Pedagogia pode ser interpretada como 8 uma estratégia de operação da ideologia, pois as IES (ao promoverem a formação inicial de professores que serão habilitados para educar e cuidar de crianças pequenas) comprovam a dissimulação que tem obnubilado relações de dominação de idade no cenário educacional brasileiro (p.127).

Este cenário torna-se mais dramático se pensarmos na qualidade desses cursos, na forma como tem sido pensada a infância e adotada uma concepção de criança e seu desenvolvimento, na pouca atenção voltada à dimensão lúdica, tudo isso somado à falta de oportunidade dada aos estudantes de cumprirem seus estágios com crianças pequenas ${ }^{9}$.

Esses e outros aspectos deveriam ser priorizados nos cursos voltados à formação inicial do educador da infância, bem como em formações pontuais, continuadas, desenvolvidas em serviço ou não.

Para agravar ainda mais a situação, a formação continuada de educadores da educação infantil não tem estado na lista das prioridades da maioria das redes de ensino que encontramos no Brasil. Muito frequentemente, quando

6 Plano Nacional pela Primeira Infância, 2010, dedica um capítulo a esta questão.

7 Ver pesquisa realizada por Lourdes Secanechia. Disponível em: < http://www.sapientia.pucsp.br/ tde_busca/arquivo.php?codArquivo=13758>. Acesso em: 15 maio 2014.

8 IES - instituições de ensino superior.

9 Cf. Plano Nacional pela Primeira Infância, RNPI, p. 86-87, 2010. 
essa modalidade de formação acontece, os educadores aprendem conceitos, estratégias e procedimentos pensados para crianças que se encontram em outro momento do desenvolvimento e não na primeira infância.

Assim, o diálogo (ou a falta dele) sobre o brincar que inicia este texto nos fez percorrer um caminho de reflexão, com proposta de apresentar alguns elementos do brincar que o validam, dentro e fora da escola. Trata-se de levantar alguns quadros de escola com os quais temos deparado, a fim de ressaltar a urgência na busca da mudança e apresentar um dos caminhos possíveis para tal - a formação continuada do educador.

Com este propósito, é premente valorizar a formação lúdica do educador, uma vez que a ludicidade é uma dimensão humana, que faz adultos e crianças se conhecerem, descobrirem seus potenciais, além de ser uma das principais linguagens utilizadas pela criança.

Esse tipo de formação faz uso de elementos da cultura (músicas, danças, artes visuais e plásticas, textos literários e científicos, filmes, entre outros, e as próprias brincadeiras) que, nas mãos dos educadores, acessam seus prazeres, desprazeres, desafios e potenciais expressivos, criativos, lúdicos, essencialmente humanos.

Individualmente ou não, eles saboreiam uma "alegria cultural”, de que necessitam para viver seus cotidianos. Como afirma Dias, apoiada nas ideias de Snyders, experimentam da "alegria como processo, como progresso que vem do enriquecimento da existência na sua totalidade, quando do casamento do conhecimento cultural com um tema essencial da vida" (DIAS, 2003, p. 233).

Em muitas escolas (ou mesmo em ambientes fora delas), o lúdico tornou-se instrumento de trabalho, não sendo visto mais como uma identificação do ser humano. Foi adotado no sentido utilitário de "brincar para", deixando de lado elementos essenciais da brincadeira - a espontaneidade, a gratuidade, o inesperado e a inteireza. Nesse sentido, sofreu um desvirtuamento, pois a ludicidade acolhe as subjetividades. No que se refere aos professores, encontrar o próprio fio lúdico, a alegria cultural, para agir dentro e fora da escola, num processo de autoconhecimento e de construção de uma atitude lúdica é fundamental. Além disso,

Na particularidade de ser professor [...] a atitude lúdica poderia comportar as subjetividades nas relações presentes na escola, rompendo barreiras e modelos, dos padrões dos quais a escola muitas vezes é vestida, deixando-se agir pela grandeza da relação com seus aprendizes, além de agir pelas concepções que acredita (LEITE, 2010, p. 14). 
Pensar o tipo de formação aqui proposto envolve ter, em sua estrutura de curso, espaço para reflexões e tomada de ações que incentivem o educador a (re)conhecer os seus alunos, suas culturas (cultura da, para e com a criança), suas necessidades, seus possíveis desafios, os seus conhecimentos, talentos e competências trazidos de casa, etc. Pretende-se, com isso, formar o educador para ouvir e olhar a criança na sua subjetividade e nas relações que ela estabelece com o grupo e com o próprio educador.

Esse tipo de formação permite e valoriza a autoria do educador, pois "só um adulto que se responsabiliza pelo seu processo criador poderá contribuir com o processo criador de seus alunos" (OSTETTO, 2007, p. 196). Só é possível mudar as práticas dos adultos com as crianças se também são questionadas as práticas dos adultos entre os adultos, dos adultos em constante formação.

Dado o contorno de uma formação lúdica, continuamos levantando seus aspectos, mas a partir de uma experiência específica, a de um projeto de formação continuada de educadores da educação infantil, o projeto Brincar. Seu foco central é refletir sobre a infância, sua cultura e brincadeiras e apoiar o educador em suas práticas profissionais.

Não por acaso, são pessoas como aquelas do diálogo apresentado inicialmente neste texto que compõem o universo da educação infantil pública, em nível de rede de ensino e de unidade escolar, os participantes desta formação. Algumas organizações não governamentais $\left(\mathrm{ONGS}^{10}\right)$ também têm feito parte do projeto. São gestores, professores, educadores sociais, monitores e outros agentes que passam a dialogar sobre a importância do brincar e como suas práticas podem, ou não, favorecer a sua presença nas escolas.

De 2005 a 2012, este projeto realizou formação continuada em muitos municípios de São Paulo, Rio de Janeiro, Minas Gerais e Paraná. Em 2013 e 2014 suas ações estão sendo desenvolvidas nos estados do Piauí, Pará e Alagoas. A formação é dada para um grupo de educadores dos municípios atendidos, procurando ter, pelo menos, um gestor (diretor ou coordenador) e dois professores de cada escola. Os professores recebem uma formação de 84 horas, sendo 64 presenciais e 20 a distância. Os gestores, além dessa carga horária, recebem mais 32 horas de formação específica para refletirem sobre suas ações que apoiam o brincar na escola.

Com a crença no educador e na potencialidade da escola pública, o projeto

10 Organizações não governamentais - ONGs - e/ou organizações da sociedade civil são definidas como organizações sem fins lucrativos, constituídas formalmente e independentes do Estado, de filiação não compulsória. 
Brincar carrega em sua raiz as seguintes diretrizes: sensibilizar e subsidiar os professores para olharem para aquilo que é próprio da infância; levar para dentro da escola a cultura da infância; fazer reconhecer as brincadeiras vistas pelos olhos das crianças.

Em seus encontros de formação, propõe aos educadores variadas experiências que têm levado à reflexão acerca de concepções como as de criança e infância, do brincar, da brincadeira como cultura, do letramento ${ }^{11}$, do papel da escola. Não se impõe uma ideia única desses termos, mas busca-se ampliar o repertório conceitual, apresentando possibilidades que, verdadeiramente, acolham a infância das crianças - brincar para o exercício da liberdade, para viver as diferenças, para fazer viver o corpo, para alimentar a alma. Para tanto, faz uso de textos, de apreciação de filmes, de discussão a distância, etc.

A participação em vivências lúdico-culturais vem permitindo aos educadores criar e viver o seu repertório lúdico-expressivo em dois níveis: compartilhamse desafios brincantes por meio de uma expressão ou linguagem plástica (desenho, pintura, modelagem), da música, jogos de raciocínio, da dança, do teatro, entre outros, e também nas brincadeiras mais conhecidas como pertencentes ao repertório infantil.

A memória da vivência da infância é tema desta formação. Recordar seu percurso de vida auxilia o educador a se colocar no lugar da criança, ter aguçada a sua curiosidade, criatividade e imaginação. Ao visitar sua memória lúdica, ele encontra sentido em se questionar se o tipo de proposta que vem fazendo ou vendo ser feita acolhe ou dá vazão a esses elementos. Brotam comentários do tipo “me vi como criança”. Nesse processo, as pessoas são “tocadas”, sensibilizadas, a emoção aflora. Lembranças de crianças diversas que brincaram ou trabalharam, solitárias ou rodeadas de outras crianças, tímidas e extrovertidas... Abre-se, assim, o horizonte para olhar as crianças que hoje estão em suas salas de aulas. Olhar para a diversidade de infâncias existentes. Todas essas experiências convidam o participante da formação a pensar onde está o seu brincar hoje.

Durante o projeto são questionados sobre as suas práticas e a aproximação delas com as concepções que o fundamentam. Muitos educadores têm se mostrado abertos e efetivamente vêm refletindo e mudando suas práticas,

${ }^{11}$ Desde 2013 passamos a incluir a temática do letramento nos conteúdos do Projeto, uma vez que as crianças estão inseridas em uma cultura letrada. Procuramos mostrar a relação da ludicidade com o letramento nessa fase da vida da criança. Propomos a reflexão em torno da importância da leitura de histórias e outros gêneros literários, do ritmo, das repetições e rimas das brincadeiras cantadas ou faladas. 
reafirmando, assim, a importância desse profissional vivenciar com seu próprio corpo diferentes expressões lúdicas, resgatar brinquedos e brincadeiras de sua própria infância, conhecer outras experiências educacionais, receber estímulos para se encorajar e se arriscar a transformar, realizar leituras e refletir em grupo sobre suas ações. É com essas ações que, aos poucos, vão sendo formados educadores que conseguem olhar mais atentamente para as crianças, deixando-as se expressarem, criarem, imaginarem, construindo “uma profissão caracterizada pela sutileza” (TRISTÃO, 2006 apud BARBOSA, 2009, p. 67). A busca é por um adulto/educador que saiba olhar a criança, dar tempo para seus atos, sustentar suas brincadeiras e interagir com elas.

O reconhecimento de que o caminho começa consigo mesmo é rapidamente percebido pelos participantes do projeto, como podemos ver no depoimento a seguir:

Eu me sinto estimulada a buscar novas reflexões sobre o brincar na educação e pretendo fazer desta reflexão um combustivel para me revigorar profissionalmente. Levo de hoje a certeza de que o primeiro passo para tornar possivel o Brincar uma atividade constante e 12 prazerosa em minha comunidade escolar começa por mim! (Marta Andrea, participante do projeto Brincar, Murici, 2014).

Com o estudo e reflexão sobre a concepção de brincar, muitos participantes ampliam suas próprias ideias e passam a investigar o seu fazer.

Sabia da importância do brincar, mas não da maneira que hoje sei. O brincar traz muitas coisas ocultas, que só um olhar investigativo pode ver. Vi que o brincar é coisa séria, a criança leva consigo para a vida todas as marcas daquilo que aprendeu (educadora, participante do projeto Brincar, Araraquara, 2010).

A partir das diferentes vivências na formação, o educador volta para si e reflete sobre o tempo que é oferecido para os fazeres das crianças. Aos poucos, ele mesmo já não separa as visões sobre a infância e o brincar.

Aprendi a tirar mais os alunos da sala de aula, deixar um pouco o registro de lado e valorizar mais as experiências com os alunos durante as brincadeiras. Explorar mais o espaço escolar e demais espaços possibilitand'o maior contato com a natureza (educadora, participante do projeto Brincar, São Carlos, 2008).

12 As diferentes falas de participantes do projeto Brincar constam em relatórios de formação escritos no período de 2005-2014, arquivados em www.sistemafvw.org.br (acesso restrito).

13 Depoimento escrito em avaliação do projeto Brincar e registrado em relatório de formação. A educadora não se identificou.

14 Idem. 
Ao retornarem para suas instituições, esses educadores contribuem para a transformação, em alguns aspectos, da prática da equipe escolar à qual pertencem, mesmo que nem toda a coletividade tenha passado pela formação.

Na instituição, houve uma maior integração entre as crianças das diversas faixas etárias,

na utilização de outros brinquedos (além daqueles industrializados), a abertura para

discutirmos quais possibilidades nós temos, sugestões e trocas de experiências e a entrada

do Brincar na Reunião de Proposta Pedagógica, com textos, brincadeiras e reflexões

(Sandra Paula, diretora de escola, participante do projeto Brincar, Araraquara, 2010).

Esses são alguns avanços alcançados com a formação deste projeto. Muitos outros exemplos poderiam ser dados, mas o importante aqui foi valorizar a necessidade de se abrir espaços para discutir e viver o campo de tensões que é a presença do brincar na escola de educação infantil. Olhar para o problema é premissa para a transformação.

Para que o direito ao brincar seja efetivado, um conjunto de ações faz-se necessário. As leis e as diretrizes curriculares que colocaram a brincadeira dentro dos princípios, concepção e objetivo das propostas pedagógicas para educação infantil constituem um importante começo. Trabalhos junto aos órgãos públicos responsáveis pela construção dos prédios escolares, formação de profissionais da educação da infância e profissionais que atuam com crianças em outros setores; atuação junto aos meios de comunicação; ampliação do debate, junto à sociedade, de maneira geral, sobre a importância da brincadeira e sobre a produção cultural para a primeira infância são outras frentes de ações que devem favorecer e garantir a brincadeira na infância.

É importante retomar o caráter gratuito da brincadeira, uma atividade livre que tem finalidade em si mesma. Quando a livre escolha das crianças (de seus pares, dos temas, objetos, espaço, tempo, etc.), a espontaneidade, a possibilidade de criação são preservados, garante-se a essência do brincar. A escola e os profissionais que nela trabalham precisam compreender e valorizar a brincadeira, transformando o espaço em local mais prazeroso e acolhedor e possibilitando protagonismo às crianças.

Quiçá, juntando esforços, veremos as inquietações trazidas no início deste texto invertidas. Veremos a equipe escolar (pedagógica e de apoio) ao lado dos pais ou responsáveis pelas crianças, observando-as e aprendendo com elas por meio de seus brincares. Quem sabe vejamos todos juntos de mãos dadas numa grande roda, brincando! 


\section{Playing at school: paths and choices}

Abstract: This article seeks to classify play as an important language children use to express themselves. It wishes to reflect upon some impasses that can be found among speeches and practices in schools for children education around this theme. It emphasizes as well how urgent it is to reflect upon practices in order to assure the right to play, pointing out the educator's upbringing on the subject of play as a possible path to this reflection. This path was conceived and designed based on reflections and experiences accumulated during the development of actions under the Brincar Project: children education, developed by Cenpec in a partnership with Fundação Volkswagen.

Key words: Play. Childhood. Educator's upbringing. Children education. 


\section{REFERÊNCIAS}

BARBOSA, Silvia. “É tudo sorvete!” - Enunciados e expressões das crianças na creche. In: KRAMER, Sonia (Org.). Retratos de um desafio: crianças e adultos na educação infantil. São Paulo: Ática, 2009.

BRASIL. Constituição da República Federativa do Brasil. Brasília, DF, Senado, 1988.

- Ministério da Educação e do Desporto. Secretaria da Educação Fundamental. Referencial curricular nacional para a educação infantil. Brasília: MEC, 1998.

- Estatuto da criança e do adolescente: lei 8.069 de 13 de julho de 1990, lei 8.242 de 12 de outubro de 1990. Brasília, DF.

. LDB Lei de Diretrizes e Bases da Educação Nacional. Lei no 9.394/96, de 20 de dezembro de 1996. Brasília, DF.

- Câmara da Educação Básica. Diretrizes Curriculares Nacionais da Educação Infantil. Resolução CEB n.1, abr. 1999. Brasília, 1999.

BROUGÈRE, Gilles. Brinquedo e cultura. São Paulo: Cortez, 2006.

CARAMBA, carambola, o brincar tá na escola. Ministério da Cultura/Cenpec. Direção Olindo Estevam. São Paulo: Paiol Filmes, 2013. 1 DVD.

CARVALHO, Ana M. A.; PONTES, Fernando A. R. Brincar é cultura. In:

et al. (Org.) Brincadeira e cultura: viajando pelo Brasil que brincar. São Paulo: Casa do Psicólogo, 2003. v. 1.

CENPEC. Projeto Brincar. Relatórios de formação de educadores de crianças: 2007-2012. São Paulo: Cenpec.

CORSARO, Willian. Sociologia da infância. Porto Alegre: Artmed, 2011.

DANTAS, Heloysa. Brincar e trabalhar. In: KHISHIMOTO, Tizuko Morchida (Org.). O brincar e suas teorias. São Paulo: Pioneira, 1998.

DIAS, Marina Célia Moraes. O direito da criança e do educador à alegria cultural. In: ; NICOLAU, Marieta Lúcia Machado (Org.). Oficinas de sonho e realidade na formação do educador da infância. Campinas: Papirus, 2003. 
KRAMER, Sonia. Formação de profissionais de educação infantil: questões e tensões. In: MACHADO, Maria L. A. (Org.) Encontros e desencontros em educação infantil. São Paulo: Cortez, 2002.

KUHLMANN Jr, Moysés. Histórias da educação infantil brasileira. In: Revista Brasileira de Educação, n. 14, maio/jun./jul./ago. 2000. Disponível em: 〈http://www.scielo.br/pdf/rbedu/n14/n14a02.pdf〉. Acesso em: 25 ago. 2012.

LEITE, Ana Maria. Caixa de brinquedos e brincadeiras: uma aliada na construção de atitude lúdica para a ressignificação da prática pedagógica do movimento na educação infantil. 2010. Dissertação (Mestrado em Educação) - Faculdade de Educação Física e Esporte, Universidade de São Paulo, São Paulo, 2010.

OSTETTO, Luciana Esmeralda. Na jornada de formação: tocar o arquétipo do mestre-aprendiz. Pro-Posições, v. 18, n. 3 (54), set./dez. 2007. Disponível em: 〈http://www.proposicoes.fe.unicamp.br/ proposicoes/textos/54-artigosostetole.pdf $\gg$. Acesso em 5 jun. 2012.

PIAGET, Jean. A formação do símbolo na criança: imitação, jogo e sonho, imagem e representação. 2 ed. Rio de Janeiro: Zahar, 1978.

REDE NACIONAL PRIMEIRA INFÂNCIA. Plano Nacional pela Primeira Infância. Brasília, 2010.

SARMENTO, Manuel Jacinto. Imaginário e culturas da infância. Disponível em 〈htpp://www.cce.udesc.br〉. Acesso em: out. 2009.

SECANECHIA, Lourdes P. Queiroz. Uma interpretação à luz da ideologia de discursos sobre bebês e a creche captado em cursos de Pedagogia da cidade de São Paulo. 2011. Dissertação (Mestrado em Psicologia Social) - Pontifícia Universidade Católica de São Paulo, 2011.

TIRIBA, Léa. Crianças da natureza. SEMINÁRIO NACIONAL: CURRÍCULO EM MOVIMENTO - PERSPECTIVAS ATUAIS, 1, 2010, Belo Horizonte. Anais... Disponível em: 〈http://portal.mec.gov.br/index.php?option=com docman\&task=doc_details\&gid=7161\&ltemid=122〉. Acesso em: 15 maio 2014.

VERDEN-ZÖLLER, Gerda. O brincar na relação materno-infantil. In: MATURANA, Humberto; VERDEN-ZÖLLER, Gerda. Amar e brincar: fundamentos esquecidos do humano. São Paulo: Palas Athenas, 2004. 
VYGOTSKY, Lev S. A formação social da mente. São Paulo: Martins Fontes, 1998.

WALLON, Henry. A evolução psicológica da criança. Lisboa: Edições 70, 1981.

WINNICOTT, Donald W. O brincar e a realidade. Rio de Janeiro: Imago, 1975.

RECEBIDO: Junho de 2014.

APROVADO: Agosto de 2014. 